\title{
ESPAÇOS AGRÁRIOS DE INCLUSÃO E EXCLUSÃO SOCIAL: NOVAS CONFIGURAÇÕES DO CAMPO BRASILEIRO
}

\section{Bernardo Mançano Fernandes ${ }^{1}$}

\section{RESUMO:}

Este artigo se apresenta dividido em três partes, na primeira, desenvolvo uma análise a respeito do atual momento da luta pela terra e da política do governo Fernando Henrique Cardoso, denominada de novo mundo rural. A segunda parte é uma breve reflexão a respeito dos conceitos de agricultura camponesa e agricultura familiar, realçando aspectos postos pela luta política na atualidade e contribuições da discussão teórica. A terceira, apresenta uma proposta de debate a respeito do sentido de uma política de reforma agrária hoje e suas perspectivas no governo Lula.

Escolhi analisar o espaço como dimensão da realidade que se configura como território e é construído por diferentes relações sociais, definindo novas configurações do campo brasileiro. Discuto diferentes espaços de inclusão como a luta pela terra por meio das ocupações, acampamentos, assentamento. Igualmente, discuto diferentes espaços de exclusão como, por exemplo, a judiciarização da luta pela terra e a agricultura familiar.

\section{PALAVRAS-CHAVE:}

Reforma agrária, agricultura camponesa, agricultura familiar, questão agrária e Estado

\section{ABSTRACT}

This paper is divided in three parts. In the first one, I develop an analysis about the current moment of struggle for land and Fernando Henrique Cardoso's government policy, called new rural world. The second part is a short reflection about the concepts of peasant agriculture and family agriculture, emphasizing aspects put by the political struggle at present time and theoretical discussion contributions. The third part presents

\footnotetext{
${ }^{1}$ Professor nos Cursos de Graduação e Pós - Graduação em Geografia da Faculdade de Ciências e Tecnologia da Unesp - campus de Presidente Prudente. Coordenador do NERA -
} 
a debate proposal about the sense of an agrarian reform nowadays and its perspectives in Lula's government.

I have chosen to analyse the space as a dimension of reality which is configured as a territory and constituted by different social relations, establishing new configurations in brazilian countryside. I discuss different spaces of inclusion such as the struggle for land by means of occupation, camping, settlements. In the same way, I discuss different spaces of exclusion, for example, judiciarization of struggle for land and family agriculture.

\section{KEYWORDS}

Agrarian reform, peasant agriculture, family agriculture, agrarian question, State.

\section{Introdução}

Para desenvolver o tema proposto, escolhi por analisar o espaço como dimensão da realidade que se configura como território e é construído por diferentes relações sociais, definindo novas configurações do campo brasileiro. É importante destacar que inclusão e exclusão social são resultados de ações políticas que se configuram num mesmo espaço, especificamente pelo caráter contraditório das relações sociais.

Desse modo, discuto diferentes espaços de inclusão, como por exemplo: a luta pela terra por meio das ocupações, acampamentos, assentamento e uma breve discussão a respeito dos conceitos de novo mundo rural e de agricultura camponesa. Igualmente, discuto diferentes espaços de exclusão, como por exemplo: a judiciarização da luta pela terra e a agricultura familiar. Por fim, faço uma reflexão a respeito da reforma agrária no governo Lula.

Neste sentido, este texto contém três partes: na primeira, desenvolvo uma análise a respeito do atual momento da luta pela terra e da política do governo Fernando Henrique Cardoso, denominada de novo mundo rural. A segunda parte é uma breve reflexão a respeito dos conceitos de agricultura camponesa e agricultura familiar. E a terceira é uma proposta de debate a respeito do sentido e as perspectivas de uma política de reforma agrária hoje. 
Este texto é uma coletânea de leituras que venho desenvolvendo a partir de minhas pesquisas, estudos e assessorias junto aos movimentos camponeses. Parte do conteúdo já foi divulgada em outros eventos, onde recebi contribuições importantes, que me ajudaram a desenvolvê-lo até este momento. Meu interesse é debater essas idéias, procurando contribuir com a compreensão do atual momento da questão agrária, pensando em políticas públicas ressocializantes e com a evolução do pensamento geográfico nesta área do conhecimento em que milito: a Geografia Agrária.

\section{Governo FHC: a judiciarização da luta pela terra e o novo mundo rural}

Estamos vivenciando um novo momento da luta pela terra, que começou a ser formado a partir da segunda metade da década de 1990. A questão agrária foi intensificada com a criação de novas políticas pelo governo Fernando Henrique Cardoso, compreendidas pela criminalização das ocupações e na implantação do Banco da Terra, na extinção da assistência técnica e na mudança do modelo de linha de crédito agrícola para a agricultura camponesa, que prejudicou o desenvolvimento socioeconômico dos assentamentos rurais.

Os objetivos dessas políticas são diversos. Podem ser sistematizados na estratégia de desarticulação das relações entre as principais instituições envolvidas com o problema agrário, principalmente dos movimentos camponeses, sindicais, e na constituição de novos espaços de representação, por meio dos conselhos de desenvolvimento rural, em diferentes escalas geográficas. Essas ações são formuladas e realizadas na produção do paradigma do capitalismo agrário.

Essa corrente teórica considera que os problemas relacionados à questão da terra, do campo e da cidade, do capital e do trabalho familiar, serão resolvidos pelo desenvolvimento do capitalismo. Dentro dessa visão de mundo, não há questão agrária. E a sua negação está no fato desta ser insolúvel na sociedade capitalista. Contudo, se é possível negar a questão, é impossível esquivar-se de seus efeitos, como por exemplo: a diferenciação social e a renda capitalizada da terra, que produzem a expropriação e a miséria.

Desse modo, pela impossibilidade de superação da questão agrária, por meio do paradigma adotado o governo FHC ajustou estrategicamente uma política de transferência e substituição dos elementos da questão agrária. Assim, os elementos, em que os trabalhadores têm perspectiva de enfrentamento e resistência nos espaço 
políticos, são transferidos para o espaço econômico, onde a resistência é reduzida. E os elementos constituídos de identidade política e histórica são substituídos por novos elementos, para a produção de outra identidade e outra história.

Desse modo, como a questão agrária só pode ser administrada no território da política, onde os trabalhadores têm poder de resistência e, por conseguinte, de enfrentamento, a intelligentsia do Governo Fernando Henrique Cardoso instituiu a idéia de "novo mundo rural”, utilizando a noção de desenvolvimento sustentável, mercantilizando a questão agrária, colocando-a no território do capital, onde os camponeses são plenamente subalternos.

Dessa forma, o governo tenta refluir a luta dos trabalhadores sem-terra, procurando desmobilizá-los; transfere a questão agrária do espaço das negociações políticas para o espaço do negócio político-econômico; ocupa o território do assentamento produzindo a idéia de empreendimento, desenvolve uma parcíssima linha de crédito, que intensifica a diferenciação social e acirra as desigualdades. Ainda, a intelligentsia do Governo Fernando Henrique Cardoso, bem como seus ministros, produziram um conjunto de eufemismos para utilizar em suas retóricas. Igualmente, procurou dar novos significados aos conceitos consagrados.

Com esse estratagema tenta nos fazer crer que o problema agrário pode ser resolvido apenas com desenvolvimento econômico, que o governo fez "a maior reforma agrária da história do Brasil”, que as “ocupações são páginas viradas da história”, que suas políticas são propositivas para o “desenvolvimento da agricultura familiar”.

Mas na realidade este estratagema faz parte do plano político do governo FHC para impedir a territorialização da luta pela terra, já que a tese da intelligentsia do governo defendia a idéia de que com a implantação de alguns assentamentos rurais, a luta pela terra diminuiria de intensidade, porque seus teóricos imaginavam que o número de famílias sem-terra era igual ao número de famílias acampadas. Pelo desconhecimento dos processos de espacialização e de territorialização da luta, seus teóricos e políticos não conseguiam compreender como a luta crescia e expandia, se o governo implantava novos assentamentos sob a pressão das ocupações de terra.

$\mathrm{Na}$ verdade, quanto mais assentamentos o governo implantava, mais a luta pela terra se espacializava e se territorializava, porque por meio desses processos, os camponeses se (re) criam. Essas ações são possibilidades políticas de (re) criação do campesinato. E recriação quer dizer intensificação da questão agrária. Para impedir esses processos, para tolher essa luta popular secular, o governo adotou nova tese e 
criou um "novo mundo rural”, onde a agricultura camponesa é metamorfoseada em agricultura familiar, procurando convencer os trabalhadores de que o mundo mudou e que a luta pela terra é coisa do passado; que a subalternidade é "natural”, na "integração ao capital e ao mercado”.

Esse “convencimento” veio acompanhado de duas medidas provisórias, em que decretou o tempo do castigo aos sem-terra, já que as famílias ocupantes de terra não são assentadas e que as terras ocupadas ficam livres do espectro da desapropriação, por um tempo determinado, deixando os latifundiários mais tranqüilos. Desse modo, tenta-se cortar pela raiz a territorialização da luta pela terra. Foi assim que o governo tirou a questão agrária do território da política e adotou o Banco da Terra, essa política do Banco Mundial, que coloca a questão agrária no território do capital, limitando as negociações políticas às condições oferecidas pelos negócios do mercado. Dessa forma, o governo se alia aos latifundiários, entorpecendo a questão agrária. E para completar esse estratagema, abandona as famílias assentadas à própria sorte, extinguindo o programa de assistência técnica, dificultando o acesso ao crédito agrícola.

Assim, os sem-terra, por lutarem para serem eles mesmos, por lutarem contra o capital e o latifúndio, são desterrados de seus espaços políticos e de seu tempo histórico. É fundamental, reafirmar que esse novo momento é resultado da inexistência de uma política de reforma agrária, da extinção dos programas de escassas políticas públicas destinadas ao desenvolvimento dos assentamentos, da criminalização das ocupações e da mercantilização da questão agrária.

Mas, na sociedade capitalista, a questão agrária é resultado de seu modo de produção que se desenvolve por meio do mercado, onde se realiza a renda capitalizada da terra, que gera a desigualdade e a diferenciação social, de modo que nesse território é impossível minimizar o efeito devastador do problema agrário. Justamente, por optar pelo mercado para conduzir essa questão, o governo precisou inventar uma outra leitura da questão agrária e idealizou o "novo mundo rural”.

Mas, ainda, como o "novo mundo rural” é uma invenção, portanto não é o mundo real, também foi preciso inventar políticas repressivas para tentar consolidar a invenção. Em tempos de ditadura, o governo utilizava-se da militarização da questão agrária, nesses tempos de democracia, o governo utiliza-se da judiciarização da questão agrária. Desse modo, ao Poder Judiciário cabe o dilema atualizado da história, em reprimir a luta pela terra, humilhando os trabalhadores, tratando-os com os mesmos recursos com que tratam os traficantes e toda bandidagem. 
Na ditadura militar, os sem-terra foram presos como subversivos. Hoje são presos para garantir a “ordem social”, como aconteceu em maio de 2002 no Pontal do Paranapanema - SP, quando o juiz de Teodoro Sampaio mandou prender todas as lideranças da região, para coibir a territorialização da luta pela terra. Assim, a estrutura fundiária, mesmo que as terras sejam griladas, permanece concentrada. E os sem-terra formam acampamentos nas beiras das estradas, que é onde eles podem ficar sem serem presos e ainda castigados com a impossibilidade de serem assentados. E assim os semterra constroem a "geografia das beiras de estradas", que é o "espaço perdido, ainda público" que resta entre os latifúndios e as estradas. Por essa razão, em 2001, a Comissão Pastoral da Terra iniciou o registro desses acampamentos, para que possamos ter uma referência dessa triste realidade, que o "novo mundo rural" insiste em desconhecer.

Ao inventar esse "mundo" também foi preciso idealizar sua leitura. Nesse contexto, os teóricos e políticos do "novo mundo rural” interpretam que com a diminuição, a ocupação de terra é "uma página virada” da história. Contudo, é importante lembrar que é a história de um mundo inventado e não de um mundo transformado. Assim, de fato, o que se tem é uma página virada da estória do "novo mundo rural".

Enquanto isso, no mundo real, a questão agrária está se intensificando. E se os números de ocupações e de famílias diminuem por meio da poder político das medidas provisórias, os trabalhadores rurais sem-terra em formação e os camponeses que se opõem a atual política agrícola do governo FHC, como por exemplo: o Movimento dos Trabalhadores Rurais Sem Terra - MST - e o Movimento dos Pequenos Agricultores MPA - estão duplicando ano a ano as manifestações. Ao analisarmos os dados relativos às manifestações, comparando os anos 1999 - 2001, observamos que triplicou o número de pessoas que participaram das manifestações na luta pela terra e para resistir na terra, que cresceu de 142 mil, em 1999, para 285 mil, em 2000, chegando a 479 mil pessoas em 2001. Sem dúvidas, estamos diante de uma das maiores manifestações populares.

São protestos das mais diversas dimensões e formas. São acampamentos e romarias, são bloqueios de estradas, são manifestações em frente aos órgãos federais e estaduais ou ocupações de prédios públicos; manifestações realizadas nas datas comemorativas da luta pela terra; são lutas dos sem-terrinha, das mulheres e dos jovens. São sem-terra, são posseiros, são pequenos agricultores, são sindicalistas: são 
camponeses. Evidente que essas manifestações representam a resistência dos camponeses que vivem no mundo real: o mundo do capital.

Portanto, é a partir deste mundo que podemos interpretar os dados do Caderno de Conflitos 2001 da Comissão Pastoral da Terra. A diminuição do número de ocupações não significa que a questão agrária está sendo minimizada. Essa é a ilusão do "novo mundo rural”, onde se acredita que é por meio da criminalização que se diminuem as ocupações de terra. O decréscimo dos números não significa que a luta pela terra seja “página virada da história”, expressa na verdade, que a estratégia da criminalização resultou nos objetivos do governo, ou seja, impedir a territorialização dos sem-terra por meio das ocupações.

As ocupações sempre foram responsáveis pelo aumento do número de assentamentos. A maior parte dos assentamentos rurais é fruto ou das ocupações de terra no Nordeste, Centro - Oeste, Sul e Sudeste ou da regularização fundiária das terras de posseiros na Região Norte. Conforme os mapas Geografia das ocupações de terra 2001, publicados nesse Caderno, observa-se que as ocupações aconteceram nas quatro regiões referidas. Na Região Norte, somente no leste do Pará ocorreram ocupações no ano de 2001. Aliás, essa realidade também pode ser observada nos mapas Geografia das ocupações de terra 1988-1999, publicados no Caderno Conflitos no Campo - Brasil 1999, p. 38-9, em que há o predomínio da luta pela terra na Amazônia Oriental.

Por essa razão é que metade das áreas dos assentamentos está na Região Norte, onde vivem 37\% das famílias assentadas, enquanto a outra metade das terras dos assentamentos está distribuída pelas regiões Nordeste e Centro - Oeste (43\%) e Sudeste Sul (7\%), onde vivem 63\% das famílias, sendo 34\% no NE, 17\% no C-O e 12\% nas regiões S e SE respectivamente. Para o mesmo período: 90\% das ocupações de terra e do número de famílias ocupantes aconteceram nas regiões Nordeste, Centro - Oeste, Sul e Sudeste, nesta ordem ${ }^{2}$. É dessa forma que posseiros e sem-terra fazem a luta pela terra, que o governo FHC chamou de “maior reforma agrária da história”.

Com a diminuição das ocupações, também diminuiu o número de assentamentos, por essa razão o governo teve que maquiar os números de 2001, como a Folha de São Paulo denunciou amplamente. Para atingir a meta de 2001, o Ministério do Desenvolvimento Agrário teve que contar famílias que só seriam assentadas em 2002 contou famílias que foram assentadas em anos anteriores e, pior, incluiu ainda milhares

${ }^{2}$ Conforme NERA. Núcleo de Estudos, Pesquisas e Projetos de Reforma Agrária. Relatório DATALUTA - Banco de Dados da Luta pela Terra - 2001. Presidente Prudente, 2002. 
de famílias que haviam preenchido as fichas da "reforma agrária pelo correio". Contabilizou também as famílias que compraram terra por meio do Banco da Terra, e as terras resultantes de regularização fundiária das áreas de posseiros. E chamou tudo isso de reforma agrária do "novo mundo rural”

Assim, no “novo mundo rural” não existem conflitos, não há ocupações de terras, não existem acampamentos de sem-terra, os assentamentos são iniciados pelo governo e em três anos, em média (sic), estão consolidados. Nesse processo extraordinário, os trabalhadores entram como sem-terra e saem como agricultores familiares, prontos para o mercado, prontos para se tornarem prósperos capitalistas.

No "novo mundo rural" vale tudo para se inventar este novo momento, desde criminalizar as ocupações a considerar famílias não assentadas como se já estivessem na terra de fato; vale transformar formulários em famílias assentadas comprar terra em nome da reforma agrária. Esses ardis do "novo mundo rural" são transformados em intensificação e refluxo da luta no mundo real, mas é interpretado como problema superado pelo governo federal.

Assim, um pesquisador desavisado pode se animar com os dados da CPT e utilizar a leitura do governo para interpretá-los, chegando a conclusão que a questão agrária está sendo resolvida. Um pesquisador mais atento e também comprometido com o rigor científico não irá analisar os números pelos números, nem tampouco crer que a diminuição dos números das ocupações de terra significa que o governo esteja fazendo a reforma agrária e, por essa razão, os sem-terra não precisariam mais lutar pela terra. O que o governo está conseguindo de fato é ter o controle social sobre os trabalhadores sem-terra. E mais, está obtendo os números que quer: diminuiu os números de ocupações por meio da criminalização e teria mantido o número de assentamentos através da astúcia e do malabarismo dos dados.

Frente aos fatos, o que os números indicam é o recrudescimento da violência, de forma sutil, tanto no campo ideológico: no território da produção das idéias para o controle social, com ampla cobertura midiática; quanto no mercado: lugar da realização da subalternidade; e finalmente por meio de medidas provisórias: esse espaço político, onde o governo, por enquanto, tem plenos poderes.

Todas essas formas contribuíram para a construção desse novo momento, intensificando a questão agrária ao tentar impedir a territorialização da luta pela terra. Por sua vez, a luta pela terra também intensifica a questão agrária. Portanto, a luta somente pode ser superada pela sua realização seja como ocupação de terra ou como 
uma política de reforma agrária. A diminuição das ocupações por meio da criminalização não representa superação do problema agrário, mas uma outra forma de intensificá-lo, de aumentar a intensidade do conflito. Na realidade as famílias sem-terra existem e a terra existe. A questão é saber até onde o "novo mundo rural” vai resistir a esta realidade.

Nesse contexto, provavelmente, um dos temas mais pertinentes referentes aos processos de controle social que foram criados e ou incorporados pelo governo FHC é a questão conceitual com o objetivo de domesticação dos movimentos camponeses. E, neste sentido, o debate a respeito dos conceitos de agricultura familiar e agricultura camponesa é essencial.

\section{Agricultura camponesa e/ou agricultura familiar: A realidade}

Durante o I Fórum Social Mundial, realizado em Porto Alegre, de 25 a 30 de janeiro de 2001, foi notável a participação da Via Campesina nas plenárias e nos diversos debates temáticos do evento. Nesse período, também foi realizado um protesto com a destruição de uma plantação experimental de soja e milho transgênicos da multinacional Monsanto, no município de Não-me-Toque - RS. Embora camponeses de diversos países do mundo tivessem participado dessa ação, a mídia deu destaque notório à participação de José Bové - um dos militantes dessa articulação, membro da Confederação Camponesa da França, e muito conhecido por causa de sua atuação, em 1999, no desmonte da loja do McDonalds, em Millau, no sul da França ${ }^{3}$.

A Via Campesina foi criada em 1992 e é uma articulação que congrega diversas organizações camponesas da Ásia, África, América e Europa. Tem como objetivo a construção de um modelo de desenvolvimento da agricultura, que garanta a soberania alimentar como direito dos povos de definir sua própria política agrícola, bem como a preservação do meio ambiente, o desenvolvimento com socialização da terra e da renda (VIA CAMPESINA, s.n.t.). No Brasil estão vinculados à Via Campesina: o Movimento dos Trabalhadores Rurais Sem Terra - MST; Movimento dos Pequenos Agricultores MPA; Movimento dos Atingidos por Barragens - MAB, Comissão Pastoral da Terra CPT e Associação Nacional das Mulheres Trabalhadoras Rurais - ANMTR.

3 A respeito: Bleil-Marques, Suzana I. Moruzzi-Marques, Paulo E. Cultural Identity Challenges Globalization: the french agricultures' confession. Inédito: 2000. 
Durante o II Fórum Social Mundial (31 de janeiro a 05 de fevereiro de 2002), novamente a Via Campesina estava presente realizando debates referentes às questões descritas. Todavia, dessa vez havia também um outro espaço ocupado pelos agricultores familiares, representados pela Federação dos Trabalhadores na Agricultura Familiar da Região Sul- FETRAF-SUL, vinculada à Central Única dos trabalhadores - CUT, também organizando debates ${ }^{4}$.

A FETRAF-SUL foi criada em março de 2001 e é um movimento sindical que reúne sindicatos de agricultores familiares e de trabalhadores rurais. Tem como objetivo fortalecer e ampliar a representação dos agricultores familiares, lutar pela reforma agrária, defender o meio ambiente e a vida com um sistema de produção sustentável. Essa organização é parte de uma forma de organização dos trabalhadores que cresceu de modo extraordinário, na década de 1990, constituindo um expressivo movimento socioterritorial (FERNANDES, 2001) e caminha para a construção de uma confederação.

\section{Agricultura camponesa e/ou agricultura familiar: a reflexão}

Há dois pontos essenciais em seus documentos que aproximam a Via Campesina e a FETRAF-SUL: a luta contra as políticas neoliberais, contra o capitalismo e pela construção do socialismo. (FETRAF-SUL, 2001).

Podemos, então, perguntar: quais as diferenças e semelhanças dessas organizações que unem as pessoas que desenvolvem o trabalho familiar e que são denominados de pequeno agricultor, pequeno produtor, agricultor familiar, camponês entre outras palavras e conceitos?

Para tentar responder esta pergunta, tomamos como referência à produção teórica recente a respeito das pesquisas relativas à agricultura familiar. Uma primeira leitura dessa questão foi realizada em FERNANDES 2001, quando destacamos o que ponderamos como os principais elementos desse debate.

Neste artigo, continuamos essa leitura que consideramos fundamental, já que essa realidade começou a ser formada na década de 1990 e desde então diversos trabalhos acadêmicos vêm sendo produzidos, especialmente em Geografia Agrária, ora tratando os conceitos de camponês e de agricultor familiar como iguais ou utilizando

\footnotetext{
${ }^{4}$ A Confederação Nacional dos Trabalhadores na Agricultura - CONTAG também realizou uma série de oficinas referentes à agricultura familiar.
} 
um desses conceitos sem a necessária reflexão teórica, de modo que o conceito de camponês aparece com o conteúdo de agricultor familiar ou vice-e-versa.

Os teóricos da agricultura familiar defendem:

que o produtor familiar que utiliza os recursos técnicos e está altamente integrado ao mercado não é um camponês, mas sim um agricultor familiar. Desse modo, pode-se afirmar que a agricultura camponesa é familiar, mas nem toda a agricultura familiar é camponesa, ou que todo camponês é agricultor familiar, mas nem todo agricultor familiar é camponês. Criou-se assim um termo supérfluo, mas de reconhecida força teórico - política. E como eufemismo de agricultura capitalista, foi criada a expressão agricultura patronal. (FERNANDES, 2001, p. 29-30).

Em uma leitura atenta dos trabalhos acadêmicos pode-se observar que os pesquisadores que utilizam o conceito de agricultura familiar com consistência teórica, não usam o conceito de camponês. Já os pesquisadores que usam o conceito de camponês, podem chamá-los de agricultores familiares, não como conceito, mas como condição de organização do trabalho. Da mesma forma, ao se trabalhar com o conceito de camponês, pode-se utilizar as palavras: pequeno produtor e pequeno agricultor. Todavia, como existem muitos trabalhos que utilizam essas palavras como equivalentes do conceito de agricultura familiar, é necessário demarcar bem o território teórico.

Os teóricos da agricultura familiar apresentam uma série de argumentos e elementos para diferenciar o agricultor familiar do camponês, como por exemplo, os trabalhos contíguos de VEIGA E ABRAMOVAY, que destacam: a integração ao mercado, o papel determinante do Estado no desenvolvimento de políticas públicas e a incorporação de tecnologias. (VEIGA, 1991, P. 190-2; ABRAMOVAY, 1992, p. 21-2).

Ainda, nessa lógica, aconteceria a transformação do camponês em agricultor familiar, como definida por LAMARCHE, 1993, p. 13-33. Numa perspectiva evolucionista, o autor parte de um modelo selvagem (sic) para um modelo ideal (sic), cujo processo seria determinado pelo projeto de vida do produtor familiar, como um complemento do projeto da sociedade para os agricultores (sic), tendo os diferentes graus de integração ao mercado como principal referência da transformação do camponês em agricultor familiar. Nessa linha de pensamento, o camponês também seria apenas o produtor de uma agricultura de subsistência. É assim que LAMARCHE 
explica a exploração e a eliminação dos camponeses, na lógica da diferenciação e da desintegração do campesinato, conceitos tão caros a LÊNIN, 1985 e KAUTSKY, 1986.

LÊNIN, 1985 e KAUTSKY, 1986 são obras seminais dos estudos da questão agrária. De modo que suas pesquisas são até hoje fundamentais para se compreender o desenvolvimento da agricultura no capitalismo. Esses trabalhos são essenciais para entender, entre outras questões, a destruição do campesinato no processo de diferenciação, e, por essa razão, estão também entre as principais referências para compreender que o espaço da luta e da resistência - para que os camponeses continuem sendo produtores familiares - não está na integração ao mercado, mas sim na luta política contra o capital. O mercado capitalista é muito mais o espaço da destruição do que da recriação do campesinato, e, em diferentes escalas, os diversos tipos de camponeses: posseiros, rendeiros, assentados, pequenos proprietários estão inseridos do mercado.

No Brasil, nos últimos vinte anos, não foi o mercado que possibilitou a recriação do campesinato, mas sim a luta política desenvolvida por meio das ocupações de terra, que se tornou a principal forma de acesso à terra. Mas, os teóricos da agricultura familiar não têm referencial para compreender esse processo. Assim, ignoraram a parte essencial da formação dos camponeses brasileiros hoje: a luta pela terra.

No final do século XIX, Lênin e Kautsky prognosticaram o desaparecimento dos camponeses no desenvolvimento desigual do capitalismo. No final do século XX, os teóricos da agricultura familiar procuram construir um método de análise em que o desaparecimento do camponês está no processo de metamorfose em agricultor familiar.

\section{Agricultura camponesa e/ou agricultura familiar: a crítica}

Dessa forma, a questão para o camponês é: ou ele se metamorfoseia em agricultor familiar e se integra ou se mantém como ele mesmo e se desintegra. Nestes referenciais não há futuro, porque não há perspectiva desse sujeito continuar sendo camponês. Na verdade, ele é visto como um estorvo para os que vêem sua desintegração, considerando que do campesinato podem surgir o capitalista e o proletário. Igualmente é visto como um estorvo para os que vêem sua integração, porque o camponês desenvolve, também, a luta contra o capital. Os primeiros querem eliminar a face conservadora do campesinato, na polêmica representação de MARX, 1979. Os segundos querem eliminar a face transformadora do campesinato, como por 
exemplo: a participação nas lutas revolucionárias do século $\mathrm{XX}$, analisada por WOLF, 1984.

A organização do trabalho familiar no campo existe desde os primórdios da história da humanidade. Em seu processo de formação, a organização do trabalho camponês realizou-se em diferentes tipos de sociedade: escravista, feudal, capitalista e socialista. No capitalismo, a sua destruição não se efetivou conforme prognosticado, porque sua recriação acontece na produção capitalista das relações não capitalista de produção e por meio da luta pela terra e pela reforma agrária (FERNANDES, 2000, p. 279-280). Assim, na não realização da destruição efetiva do camponês, tenta-se refutar o conceito.

Um exemplo da refutação do conceito de camponês está em HESPANHOL, 2000, onde afirma:

que a utilização na década de 1990, da categoria de análise agricultura familiar para designar genericamente as unidades produtivas, nas quais a terra, os meios de produção e o trabalho encontram-se estreitamente vinculados ao grupo familiar, deve ser aprendida como um reflexo das alterações recentes ocorridas na agricultura brasileira e que, em última análise, levaram a valorização do segmento familiar. Nesse sentido, as categorias de análise até então utilizadas para caracterizarem essas unidades de produção, como campesinato, pequena produção, agricultura de subsistência, produção de baixa renda, entre outras, perderam seu poder explicativo, favorecendo à emergência de novas concepções teóricas consubstanciadas na categoria agricultura familiar. (HESPANHOL, 2000, p. 2).

Se concordássemos com essa tese, poderíamos desconsiderar trabalhos a respeito do campesinato, que são importantes referências teóricas na Geografia, como a obra Agricultura Camponesa no Brasil, de OLIVEIRA, 1991, na Sociologia, que é o belo trabalho de TEDESCO, 1999, denominado: Terra, trabalho e família: racionalidade produtiva e ethos camponês. Ainda, na Antropologia, como por exemplo, o clássico Herdeiros, parentes e compadres, de WOORTMANN, 1995, entre tantos outros. De fato, o conceito de camponês não perdeu o seu poder explicativo. Caso contrário, as pesquisas realizadas, que tomaram como referências teóricas as obras citadas, não conseguiriam explicar os problemas que se propuseram compreender. Ainda, na realidade estudada por HESPANHOL, 2000, aconteceu um processo de diminuição do 
campesinato, mesmo com a intensa luta dos sem-terra na região do Pontal do Paranapanema, que resultou, no período de 1984-2000, na conquista de 79 assentamentos, onde foram assentadas 4.597 famílias (FERNANDES e RAMALHO, 2001).

O fato de grande parte dos trabalhos acadêmicos recentes utilizarem o conceito de agricultora familiar não significa que o conceito de camponês perdeu seu status teórico ${ }^{5}$. Uma coisa é a opção teórica e política dos cientistas frente aos paradigmas, o que é extremamente diferente da perca do status de um conceito. Vivemos hoje um momento histórico em que a febre do fim das coisas e dos conceitos tem contaminado e modelado diversos pesquisadores. Por exemplo: o fim da história, o fim do trabalho, o fim da ciência entre outros fins. Com relação ao campesinato, neste artigo defendemos o fim do fim do campesinato, para que possamos analisar com eficiência essas novas realidades que acontecem em escala mundial, representada pela Via Campesina e pelas organizações de agricultores familiares.

Em um estudo, com ponderação, do referencial teórico da agricultura familiar, pode-se analisar uma predominante racionalidade econômica que permite uma compreensão parcial, mas não o aprofundamento da análise da questão agrária ${ }^{6}$, como pode ser observado em um pensamento conclusivo do estudo de HESPANHOL:

Com o agravamento dos problemas enfrentados por esses produtores (exaustão dos solos, baixa produtividade das culturas, baixos preços para os produtos agrícolas, dificuldades de acesso ao crédito rural, etc.) associado a intensificação da concentração fundiária resultante da expansão das áreas de pastagens, levaram a descapitalização crescente dessas explorações familiares, resultando numa menor capacidade de absorção de força de trabalho e a conseqüente expulsão de um expressivo contingente populacional. (HESPANHOL, 2000, p. 322).

O processo de empobrecimento e expropriação das famílias trabalhadoras rurais tem como causa principal a sujeição da renda da terra ao capital, que determina os fatores analisados por HESPANHOL. Portanto, a questão é de subordinação - cujo

\footnotetext{
${ }^{5}$ Mesmo que um dos principais teóricos do campesinato brasileiro também tenha adotado o termo agricultura familiar em seus últimos trabalhos, sua obra continua sendo uma das principais referências para o estudo do campesinato. É o caso de MARTINS, 2001.

${ }^{6}$ Importante destacar: é na questão agrária que está inserido o debate teórico: campesinato e ou agricultura familiar.
} 
caráter principal é político. Como os camponeses não se apropriam da maior parte da riqueza produzida pelo seu trabalho, necessária para o seu desenvolvimento socioeconômico, inicia-se um processo de decadência das unidades familiares, levando ao êxodo, com a concentração de renda e da propriedade nas mãos dos capitalistas.

A construção teórica da agricultura familiar tem construído a compreensão e a percepção que o camponês representa o velho, o arcaico e o atraso, enquanto o agricultor familiar representa o novo, o moderno, o progresso. Evidente que os custos políticos dessas formas de entendimento são altíssimos para os movimentos camponeses.

\section{Agricultura camponesa e/ou agricultura familiar: a consideração}

Nesse contexto de embate científico e político, será preciso muito esforço dos teóricos da agricultura familiar para convencer os camponeses organizados na Via Campesina, que sua luta não tem futuro. Que, fatalmente, vão se transformar em agricultores familiares. Resta conhecer como os denominados agricultores familiares organizados na FETRAF-SUL discutirão a luta pelo socialismo, se a lógica do pensamento que originou o conceito que eles materializaram não tem essa perspectiva.

Ainda nesta consideração quero destacar uma outra leitura importante a respeito do tema em questão. Refiro-me ao texto de Neves, 2001. A autora, numa análise filosófica do termo de agricultura familiar, salienta:

“...não reconheço o termo agricultura familiar como conceito teórico. Ele é descritivo e politicamente classificador de um segmento de produtores instado a um projeto de redefinição de suas formas de integração. Os pesquisadores não podem usá-lo se esquecendo que o trabalho político de reconhecimento social implica a eufemização dos significados subjacentes à categoria...

Ele [o termo] pressupõe a superação do insulamento político cultural e da precariedade material dos camponeses, dos pequenos produtores, dos arrendatários, dos parceiros, dos colonos, dos meeiros, dos assentados rurais, dos trabalhadores sem - terra. Portanto, a categoria de agricultura familiar acena para um padrão ideal de integração diferenciada de uma heterogênea massa de produtores a trabalhadores rurais. E se legitima por um sistema de atitudes que lhe está associado, que denota a 
inserção num projeto de mudanças da posição política e, por isso, da secundarização do papel econômico e social.

Portanto, trata-se de uma categoria de ação política que nomeia um amplo e diferenciado segmento mobilizado à construção de novas posições sociais mediante engajamento político.” (Neves, 2001, p. 2-3, grifos da autora)

A leitura de Neves é uma importante contribuição para o debate a respeito deste tema. Ela delineia a corrente teórica em que o termo foi instado e os limites que o mesmo apresenta para ser considerado um conceito.

Esta é uma discussão recente. Desde que o termo apareceu em princípios da década de 1990, não houve críticas em sua utilização. Utilizou-se o termo sem critérios, como é comum, principalmente na Geografia, quando se importam conceitos sem conhecer os seus significados.

No XIV ENG, realizado em dezembro de 2000, na cidade de Goiânia, pela primeira vez, debatemos essa questão. No Encontro da Associação Nacional Pós Graduação em Geografia, realizado em abril de 2002, em São Paulo, tivemos os primeiros interlocutores e no XIII Encontro Nacional de Geógrafos, realizado em João Pessoa, no mês de julho de 2002, promovemos a primeira mesa coordenada a respeito do tema. Com este texto, procuramos dar continuidade ai debate.

Dentro do contexto que desenvolvemos até aqui e frente a vitória histórica de Lula para presidente da república, propomos a reflexão a respeito da questão agrária em um governo do Partido dos Trabalhadores.

\section{O Governo Lula e a questão agrária}

Neste ensaio, nosso objetivo é propor o debate a respeito do sentido e as perspectivas de uma política de reforma agrária hoje.

Apresentamos três questões para promover o debate, procurando abordar o tema a partir dos principais paradigmas teóricos, tendo como referência uma análise da realidade da questão agrária nas últimas três décadas e realizando uma reflexão a respeito da continuação da política de implantação de assentamentos rurais e da reforma agrária necessária.

Neste sentido, discutimos os paradigmas que denominamos como: da desintegração do campesinato, da agricultura familiar e da produção capitalista das 
relações não capitalista de produção. Analisamos as formas como abordam a questão da reforma agrária e as suas perspectivas.

Desses referenciais teóricos, partimos para uma reflexão das possibilidades da territorialização dos assentamentos rurais por meio da luta pela terra e concluímos com a compreensão da impossibilidade hoje da realização da reforma agrária necessária.

\section{Os paradigmas da Questão Agrária hoje}

A reforma agrária é um dos elementos da questão agrária. É uma política pública - de caráter institucional - da sociedade capitalista, cuja instituição competente para realizá-la é o Estado, no caso do Brasil: o governo federal.

Nosso país tem como marca história a luta pela reforma agrária movida por meio da luta pela terra. Em nossas pesquisas temos demonstrado que a luta pela terra - que compreendemos como uma política pública de caráter popular - tem promovido nas últimas décadas grande pressão para que diversos governos implantassem diferentes políticas de assentamentos rurais.

Desse modo, afirmamos que nunca existiu uma política de reforma agrária no Brasil (FERNANDES, 1996, 2000, 2001), embora o governo tenha propagandeado e diversos cientistas tenham utilizado essa expressão para falar das políticas de assentamentos rurais, como por exemplo MARTINS, 2000 e 2001.

Os paradigmas da questão agrária hoje possuem distintas visões a respeito da reforma agrária. Desde esses pontos de vista temos várias compreensões referentes ao problema, que se interagem, se misturam e se distanciam, contribuindo ora para o seu desenvolvimento, ora para o seu emperramento.

O paradigma da desintegração do campesinato que relaciona o tema, com as atividades não - agrícolas, com o assalariamento, ou até mesmo com o salário desemprego como políticas públicas para os trabalhadores rurais expulsos ou expropriados do campo.

O paradigma da agricultura familiar que defende a diferenciação entre agricultura camponesa e agricultura familiar, propondo a "integração ao capital e ao mercado” como formas modernas de desenvolvimento do campo, aceitando políticas de compra e venda de terra como condição de acesso à terra.

O paradigma da produção capitalista das relações não capitalista de produção que compreende, na lógica desigual e contraditória do desenvolvimento da agricultura 
no capitalismo, as possibilidades de (re) criação o campesinato, desde por meio dos processos econômico - geográficos, como por exemplo: o arrendamento da terra e da migração; como pelos processos de espacialização e territorialização da luta pela terra, como por exemplo: as ocupações de terra.

O paradigma da desintegração do campesinato não vê a reforma agrária como uma política importante para o desenvolvimento da agricultura, pois considera a agricultura capitalista como predominante e essencial. Nesse sentido, a reforma agrária é uma política compensatória e deve considerar principalmente as atividades não agrícolas, conforme a tendência da pluriatividade.

O paradigma da agricultura familiar entende como reforma agrária as políticas que possibilitem o acesso à terra, mesmo que por meio de compra e venda, privilegiando a integração ao mercado, por meio da especialização da produção em determinados sistemas agrários. Defende a capitalização e a diferenciação dos agricultores como processos do desenvolvimento do capitalismo agrário.

O paradigma da produção capitalista das relações não capitalista de produção compreende a reforma agrária como uma política importante de distribuição da terra, como forma de recriação do campesinato ou para impedir a sua destruição. O mercado e a capitalização são processos que devem ser pensados no campo da luta e da resistência. Ao contrário dos outros paradigmas, neste, a luta pela terra é considerada como uma forma essencial para a formação do campesinato.

Uma questão importante nesses paradigmas é o sujeito do processo. Quando o campesinato é sujeito, quando é o capital e ou o Estado. Tanto na academia quanto nos governos e nas políticas públicas, essas correntes teóricas estão presentes e determinam os rumos das políticas e da luta pela reforma agrária.

Da mesma forma, encaminham as políticas de crédito, de educação, de produção e de organização dos assentamentos. Evidente que as significações aqui apresentadas são iniciais, mas também são referenciais para um debate e para o aprofundamento necessário, que pretendemos realizar.

\section{Luta pela terra e a política de implantação de assentamentos rurais.}

No governo Lula, não tenho a expectativa da realização de uma política de reforma agrária. Acredito que será realizada uma ampla política de assentamentos rurais. Desse modo, a luta pela terra e a política de implantação de assentamentos rurais 
tendem a ser os processos que já conhecemos desde o século passado. Com avanços e refluxos, de acordo com as correlações de forças das ações dos movimentos socioterritoriais, dos partidos políticos e dos governos. Nada mais do que isso.

Nos últimos trinta anos, essa tem sido a tendência e não há novos referenciais na realidade que indiquem o contrário. Nem mesmo o governo do Partido dos Trabalhadores possibilitará a realização da reforma agrária.

As razões dessa afirmação são: os trabalhadores não têm maioria no Congresso Nacional para mudarem a correlação de formas, hoje dominada pelos ruralistas. Por outro lado, o Poder Judiciário continua forte na defesa dos interesses e dos privilégios dos latifundiários.

Isso não significa que não teremos avanços na luta pela terra e na intensificação de assentamentos rurais. Mas, como já afirmamos isso não é reforma agrária. Também é possível que tenhamos políticas agrícolas voltadas para o interesse da agricultura camponesa e, com certeza, as medidas provisórias que criminalizam as ocupações não serão reeditadas.

\section{A reforma agrária necessária}

O Brasil tem a segunda maior concentração de terras do mundo e está entre os dez países com maior índice de desigualdade. A reforma agrária ao atingir a estrutura fundiária concentrada, democratizando o acesso à terra, modificará essa conjuntura.

As famílias beneficiadas poderão ser tanto de origem rural quanto de origem urbana. Uma política de reforma agrária não pode deixar de atender a população urbana interessada em construir suas vidas no campo. Hoje, nos assentamentos há famílias assentadas que nunca tinham vivido como produtoras agrícolas. Por meio da luta, elas encontraram na terra uma possibilidade de reconstruir suas vidas com dignidade.

Pela história de grilagem da terra do Brasil, não é aceitável uma política de mercantilização de terra. Reforma agrária é desapropriação É ação do Estado e não política de mercado. 


\section{Bibliografia}

ABRAMOVAY, Ricardo. Paradigmas do capitalismo agrário em questão. São Paulo Rio de Janeiro - Campinas: Editora Hucitec - ANPOCS - Editora da Unicamp, 1992.

BLEIL-MARQUES, Suzana I. MORUZZI-MARQUES, Paulo E. Cultural Identity Challenges Globalization: the french agricultures’ confession. Inédito: 2000.

FERNANDES, Bernardo Mançano. MST: formação e territorialização em São Paulo. São Paulo, Editora Hucitec, 1996.

FERNANDES, Bernardo Mançano. A Formação do MST no Brasil. São Paulo, Editora Vozes, 2000.

FERNANDES, Bernardo Mançano. Questão Agrária, Pesquisa e MST. São Paulo, Cortez Editora, 2001.

FERNANDES, Bernardo Mançano. RAMALHO, Cristiane Barbosa. Luta pela terra e desenvolvimento rural no Pontal do Paranapanema. Estudos Avançados no 43. p.239254, 2001.

FETRAF-SUL. O sindicato é o Caminho. (folder), 2001.

GÓMEZ, Jorge R. Montenegro. Desenvolvimento e controle social: releitura das novas políticas públicas e desenvolvimento rural para o Noroeste Paranaense. Maringá, 2001. Relatório de Qualificação (Mestrado em Geografia). Programa de Pós - Graduação da Universidade Estadual de Maringá.

HESPANHOL, Rosângela Aparecida de Medeiros. A produção familiar: perspectivas de análise e inserção na microrregião geográfica de Presidente Prudente. Rio Claro, 2000. Tese (Doutorado em Geografia). Programa de Pós - Graduação em Geografia do Instituto de Geociências e Ciências Exatas da Universidade Estadual Paulista.

LAMARCHE, Hugues (Coord.) A Agricultura Familiar: uma realidade multiforme. Campinas: Editora da Unicamp, 1993.

LAMARCHE, Hugues (Coord.) A Agricultura Familiar: do mito a realidade. Campinas: Editora da Unicamp, 1998.

KAUTSKY, Karl. A questão agrária. São Paulo: Nova Cultural, (1899) 1986.

LÊNIN, Vladimir Ilich. O desenvolvimento do capitalismo na Rússia. São Paulo: Nova Cultural, (1899) 1985.

MARTINS, José de Souza. Reforma Agrária: o impossível diálogo. São Paulo: Edusp, 2000. 
MARTINS, José de Souza. Impasses sociais e políticos em relação à reforma agrária e à agricultura familiar no Brasil. www.nead.org.br, 2001.

MARX, Karl. El capesinado como clase. In SHANIN, Teodor. Campesinos e Sociedades Campesinas. México: Fondo de Cultura Económica, 1979.

NEVES, Delma Peçanha. A agricultura familiar e o claudicante quadro institucional. Inédito: 2001.

OLIVEIRA, Ariovaldo Umbelino de. A agricultura camponesa no Brasil. São Paulo: Contexto, 1991.

TEDESCO, João Carlos. Terra, trabalho e família: racionalidade produtiva e ethos camponês. Passo Fundo: UPF - Editora, 1999.

VEIGA, José eli. O Desenvolvimento Agrícola: uma visão histórica. São Paulo: Hucitec, 1991.

VIA CAMPESINA. Linhas Políticas. s.n.t.

WOLF, Eric, R. Guerras Camponesas do Século XX. São Paulo: Global, 1984.

WOORTMANN, Ellen F. Herdeiros, parentes e compadres. São Paulo: Brasília: Hucitec: Editora da UnB, 1995. 